\title{
Proses Penalaan Piano di Jurusan Musik FSP ISI Yogyakarta
}

\author{
Lutfia Okta \\ Alumni Jurusan Musik, Fakultas Seni Pertunjukan, Institut Seni Indonesia Yogyakarta; telp. \\ 085643145048; e-mail: luvi_0810@yahoo.com \\ Eritha R. Sitorus \\ Lektor pada Jurusan Musik, Fakultas Seni Pertunjukan, Institut Seni Indonesia Yogyakarta; \\ telp. +62851004543757; e-mail: erithasitorus@gmail.com \\ Debora R. Yuwono \\ Lektor pada Jurusan Musik, Fakultas Seni Pertunjukan, Institut Seni Indonesia Yogyakarta; \\ Telp.: +62816683745
}

\begin{abstract}
The name piano is derived from the word pianoforte, an acoustic keyboard instrument that can produce varying tone volumes from soft to hard, which in previous developments such capacities are not present. Season changes may result in a change of tension levels of over 200 piano strings so that these instruments need to be routed. This study examines the tenure of piano tuning by piano technicians at Music Department, the Faculty Performing Arts of, Indonesian Institute of the Arts. Through observational approach the author observed the tuning process, which was basically the alignment of the strains of the piano strings in accordance with the standard of note pitches in order to reach the best level of accuracy. The results of this study indicate that the piano tuning system applied in Music Department was the equal tempered system, which divided an octave into equal 12 tones. Among the equal tempered system stages was to tune the A4 tone at an altitude of $440 \mathrm{~Hz}$. The three strings that support a tone should be tuned so that all the three could reach the same pitch of the tone. Piano tuning uses a tool called hammer tuner. With the tool the tempered tones are strung from E3 to Bes4 as a benchmark for stringing up the tone (the above notes) and basing (the notes below).
\end{abstract}

Keywords: Piano; tuning, equal temperred.

\begin{abstract}
Abstrak
Piano berasal dari kata pianoforte, yaitu sebuah instrumen keyboard akustik yang dapat menghasilkan volume nada yang bervariasi dari lunak hingga keras, yang di pada perkembangan sebelumnya kapasistas tersebut tidak terdapat. Pergantian musim dapat mengakibatkan perubahan tingkat ketegangan lebih dari 200 senar piano sehingga instrumen ini perlu ditala secara rutin. Penelitian ini mengkaji tenik penalaan piano oleh teknisi piano di Jurusan Musik, Fakultas Seni Pertunjukan Institut Seni Indonesia Yogyakarta. Melalui pendekatan observasi peneliti mengamati proses penalaan yang pada dasarnya adalah penyelarasan ketegangan senar-senar piano sesuai dengan standar bunyi musikal agar hasil talaan dapat mencapai tingkat akurasi yang terbaik. Hasil penelitian ini menunjukkan bahwa sistem penalaan piano yang digunakan di Jurusa Musik hingga saat ini adalah sistem equal tempered, yaitu membagi oktaf menjadi 12 nada secara rata. Di antara tahap awal dari sistem equal tempered yang telah dilakukan ialah dengan cara menala nada A4 pada ketinggian $440 \mathrm{~Hz}$. Untuk selanjutnya ketiga senar yang mendukung sebuah nada ditala sehingga ketiganya mencapai ketinggian yang sama pada nada tersebut. Penalaan piano menggunakan alat yang disebut hammer tuning. Dengan alat tersebut nada-nada tempered dirangkai dari E3 hingga Bes4 sebagai patokan untuk merangkai nada diskan (nada-nada di atas) dan baskan (nada-nada di bawah).
\end{abstract}

Kata kunci: Piano; penalaan; equal temperamen. 


\section{Pengantar}

Penalaan nada (tuning), atau yang lebih dikenal dengan sebutan stem, merupakan hal yang sangat penting bagi semua instrumen musik, baik yang tradisional maupun modern, karena sebelum instrumen tertsebut dimainkan harus ditala terlebih dahulu untuk menghasilkan suara yang sempurna. Penalaan pada instrumen "Barat", khususnya yang digunakan pada orkes simfoni, mempunyai standarisasi keting-gian A4 sama dengan $440 \mathrm{~Hz}$ (Culver, 1956: 114). Oleh sebab itu setiap musisi harus dapat menala instrumennya masing-masing, kecuali untuk instrumen piano yaitu instrumen pukul yang mempunyai lebih dari 200 senar. Untuk menala instrumen piano dibutuhkan tenaga ahli yang terlatih secara khusus dan memakai alat-alat khusus.

Penalaan pada piano berarti menyesuaikan ketegangan dari masing-masing senar piano dengan menggunakan palu tala (hammer tuning) sehingga setiap senar terdengar selaras dengan senar lain yang sesuai dengan hukum akustik. Faktor yang mempengaruhi ketegangan pada senar piano yaitu di karenakan kelembaban udara yang tinggi dari musim hujan ke musim kemarau.

Perubahan kelembaban udara dapat mempengaruhi tegangan pada senar piano, baik itu piano baru atau bekas, dipakai maupun tidak. Semua perlu ditala secara berkala, seharusnya dua kali dalam setahun sesuai dengan kondisi perubahan musim di Indonesia.

Pada saat musim hujan ketegangan senar akan cenderung me-ningkat dan sebaliknya dalam cuaca kemarau (panas) ketegangan senar piano akan cenderung menurun, dan itu semua akan membuat tinggi rendahnya suara piano (pitch) akan berubah (Fine, 1950: 168).

Pada saat memindahkan letak piano maka sebaiknya piano juga ditala, karena pergeseran piano yang menyebapkan goncangan juga berakibat tegangan pada senar berubah. Penalaan tidak termasuk perbaikan seperti yang sering dianggap oleh masyarakat umumnya.

Dalam mempelajari proses penerapan penalaan piano sebelumnya harus mengetahui tentang awal mula perkembangan dari terbentuknya sistem penalaan. Sistem equal tempered adalah sistem penalaan yang digunakan sampai saat ini untuk menala instrumen, karena sistem ini lebih sempurna digunakan pada piano dibandingkan dengan sistem penalaan sebelumnya. Awal terbentuknya sistem penalaan dimulai dari sistem phytagorean intonation yaitu sistem penalaan yang di dasarkan pada oktaf dan kwint, kemudian berkembang pada system just intonation yaitu sistem penalaan yang di dasarkan pada oktaf, kwint, dan terts. Setelah itu muncul sistem yaitu mean-tone temperament. Namun ke tiga sistem di atas dalam penalaan piano tidak bisa digunakan karena pembagian nada tidak rata/ unequal (menimbulkan masalah bunyi pada instrumen piano), karena itu dikembangkan lagi sebuah sistem baru yaitu sistem equal temperament. Sebuah sistem yang membagi oktaf menjadi 12 nada secara kromatis dengan ukuran yang sama, biasanya disebut sebagai nada kromatis dari dua frekuensi yang dipisahkan oleh semitone yang sama.

Penelitian mengenai proses penalaan pada piano dilakukan di Jurusan Musik Fakultas Seni Pertunjukan (FSP) Institut Seni Indonesia (ISI) Yogyakarta, dengan cara mengikuti saat proses penalaan berlangsung. Selain itu juga wawancara dengan nara sumber (tukang stem) yaitu, Drs Musmal, M.Hum., yang sejak kira-kira tahun 1990 sampai dengan sekarang menala dan merawat piano yang ada di Jurusan Musik Fakultas Seni Pertunjukan Institut Seni Indonesia Yogyakarta. Penelitian juga di dasarkan pada instrumen mayor peneliti yaitu instrumen piano, dengan minat utama Musik Pendidikan. 


\section{Pembahasan}

\section{Peralatan Penalaan Piano}

Penala piano di Institut Seni Indonesia Yogyakarta memiliki beberapa peralatan yang tepat digunakan untuk menala piano. Peralatan yang digunakan adalah peralatan penalaan yang umum digunakan oleh setiap penala piano, dan ada juga yang dibuat sendiri oleh Musmal (penala), yaitu sejenis stick mutes yang dibuat dari karet. Ada beberapa jenis peralatan yang umum digunakan untuk menala piano, yaitu: tuning fork, hammer tuning, wedge mutes, dan tuning tip.

\section{a. Tuning fork (Garpu Tala)}

Tuning fork (garpu tala) adalah sebuah perangkat logam digunakan sebagai alat resonator untuk menetapkan pitch. Alat ini ditemukan pada tahun 1711 oleh John Shore. Keuntungan alat ini adalah pitch tidak terpengaruh sama sekali oleh perubahan suhu, alat ini berfungsi untuk mempertahankan pitch secara permanen. Alat ini digunakan untuk menyesuaikan pitch standar internasional. Cara penggunaannya adalah pegang batang garpu tala dan pukulkan ujungnya dengan keras, kemudian sentuhkan batang garpu tala ke bagian kayu dari piano, dan kayu akan memperkuat suara garpu tala. Pada samping pegangan garpu tala tercetak tulisan yang menunjukkan bahwa garpu tala tertsebut menghasilkan standar pitch (Lindley, 1980: 887). Garpu tala memiliki tiga jenis ukuran pitch yaitu pertama pada C4 ( $\mathrm{C}$ tengah) dengan ukuran pitch 261,6. Ke dua yaitu pada nada A4 di atas C4 dengan ukuran pitch A4 $440 \mathrm{~Hz}$. Ke tiga adalah di atas $\mathrm{C} 4$ dengan ukuran pitch 523,3.

Penala saat ini lebih banyak yang menggunakan tuner dibanding garpu tala untuk menetapkan pitch yang digunakan yaitu A4 $440 \mathrm{~Hz}$, di karenakan lebih mudah dan lebih cepat. Penala di ISI Yogyakarta juga menggunakan tuner untuk menala pitch pada nada A4 $440 \mathrm{~Hz}$.

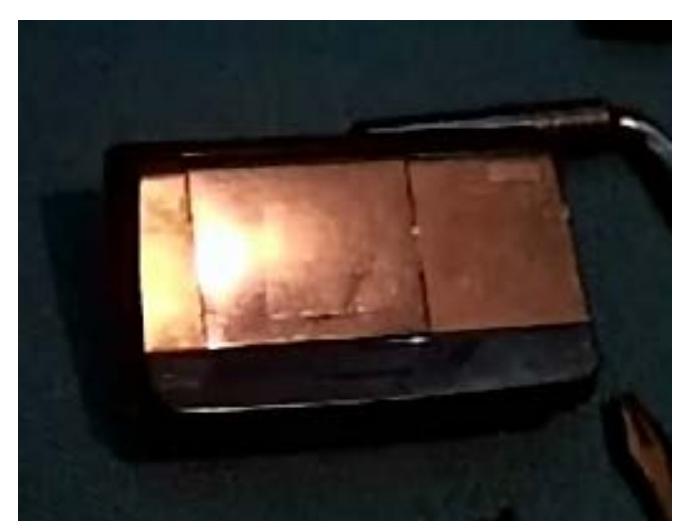

Ilustrasi 1.

Tuner (Dokumentasi: Lutfi, 2013).

b. Tuning hammer

Tuning hammer adalah alat untuk mengatur ketegangan pitch masing-masing nada pada senar dengan memutar tuning pin dengan cara dihentakkan, sehingga dapat menaikan atau menurunkan tegangan senar. Satu ukuran tuning hammer cocok untuk semua jenis tuning head.

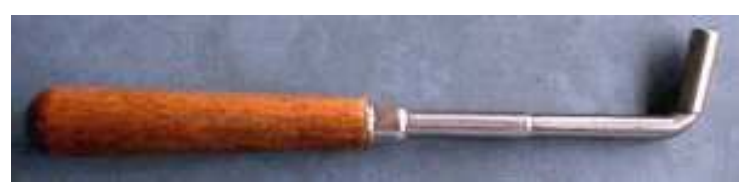

Ilustrasi 2.

Tuning hammer (Dokumentasi: Lutfi, 2013).

Tuning head memiliki ukuran berbeda sesuai dengan penggunaannya, pada ujung piano digunakan tuning head dengan ukuran lebih tinggi agar posisi memutar hammer lebih mudah.

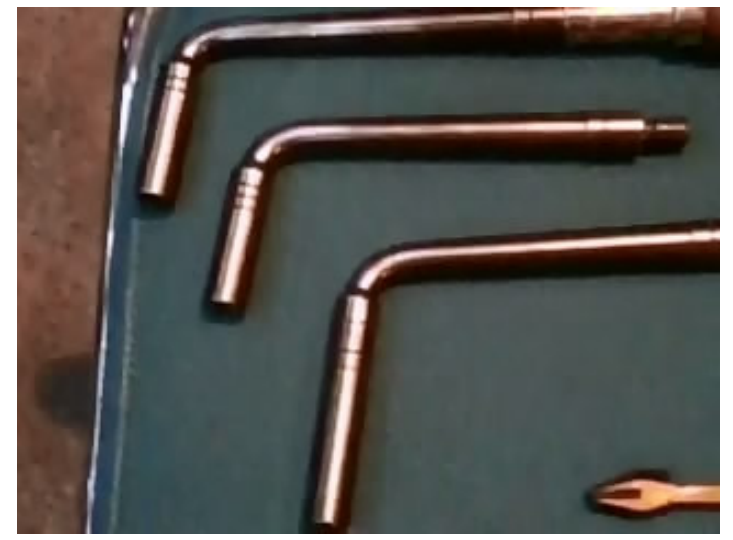

Ilustrasi 3:

Tuning head (Dokumentasi: Lutfi, 2013). 
c. Wedge mutes \& Stick mutes

Wedge mutes, yaitu alat penghenti bunyi terbuat dari ruber/ karet. Alat ini digunakan untuk meredam senar senar agar tidak berbunyi/ bergema saat penalaan sebuah dawai dilakukan. Lebih dari empat Wedge mutes digunakan dalam satu penalaan sebuah nada. Sebagai contoh ialah setelah menala A4 $440 \mathrm{~Hz}$, masing-masing wedge mutes diletakkan pada sisi kanan senar Cis4, F4, dan A4 ditala sementara sisi kiri senar diredam. Setelah sisi kanan senar ditala dengan benar kemudian alat diletakkan bergantian ke sisi kanan untuk meredam senar dan sisi kiri senar ditala.

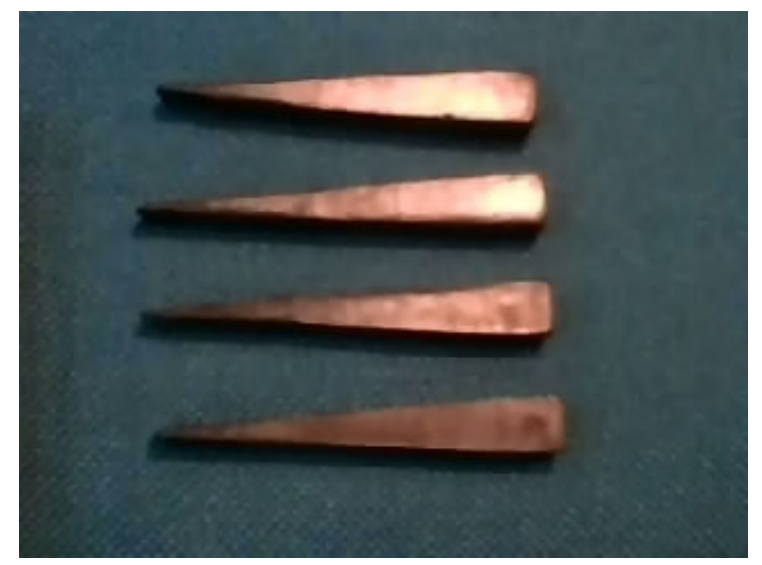

Ilustrasi 4:

Wedge mutes/Damper (Dokumentasi: Lutfi, 2013).

Stick mutes sering digunakan pada penalaan jenis piano upright. Fungsi penggunaan stick mutes pada senar sama dengan wedge mutes. Cara penggunaannya yaitu ujung stick mutes di letakkan pada satu senar sebagai peredam, sebagian senar yang tidak diredam kemudian ditala dan diputar dengan menggunakan hammer.

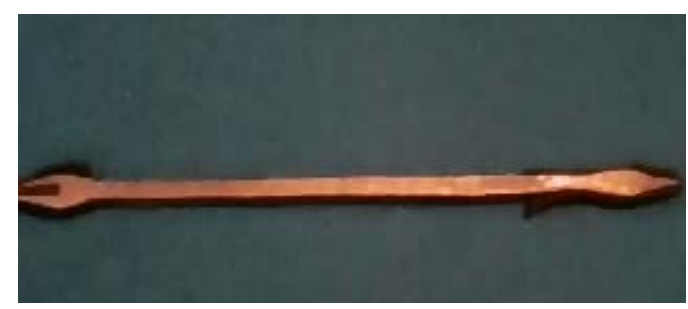

Ilustrasi 5:

Stick mutes (Dokumentasi: Lutfi, 2013).
Stick mutes sangat berguna pada saat menala senar yang dekat dengan plate (kerangka besi).

\section{d. Muting felt}

Alat ini digunakan untuk menyelesaikan tugas yang sama dengan wedge mutes. Muting felt untuk menala beberapa senar, tanpa atau di samping menggunakan wedge mutes.

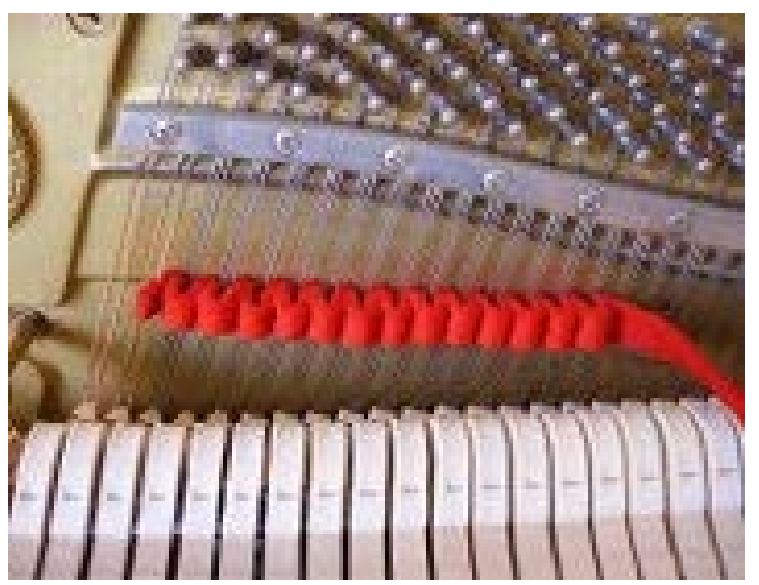

Ilustrasi 6

Muting felt (Dokumentasi: New Octave, 2013).

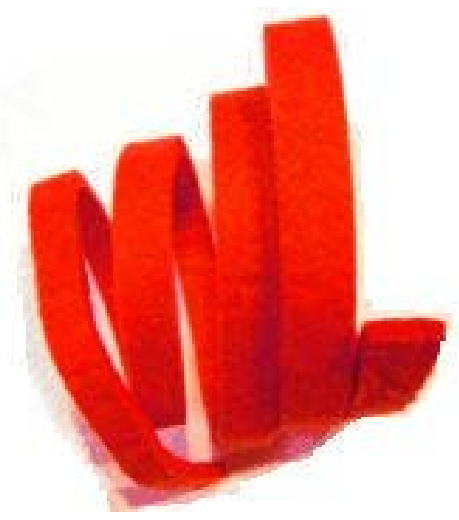

Ilustrasi 7:

Bahan muting felt (Dokumentasi: new octave, 2013).

Muting felt disisipkan antara senar dengan obeng yang tipis atau alat lainnya. Muting felt untuk mematikan bagian luar dari tiga senar unison atau serempak. Pada senar bagian luar diredam sehingga senar tengah bebas bergetar dan kemudian ditala. 


\section{e. Tuning Tip}

Tuning tip adalah alat yang dipasang pada kepala hammer tuning. Tuning tip memiliki tiga jenis yaitu, square tuning tip, oblong tuning tip dan star head tuning tip. Tuning tip yang digunakan pada piano modern adalah Star head dan memiliki beberapa ukuran yaitu sebagai berikut: \# 1/0 $(0,276 " / 7.01 \mathrm{~mm})$, \# 2/0 (0,282 "/ 7.16mm), \# 3/0 (0,286 "/ 7.26 $\mathrm{mm})$. Tuning tip ukuran \#2 adalah ukuran yang paling umum ditemukan pada hampir semua piano yang diproduksi di seluruh dunia selama 100 tahun terakhir.

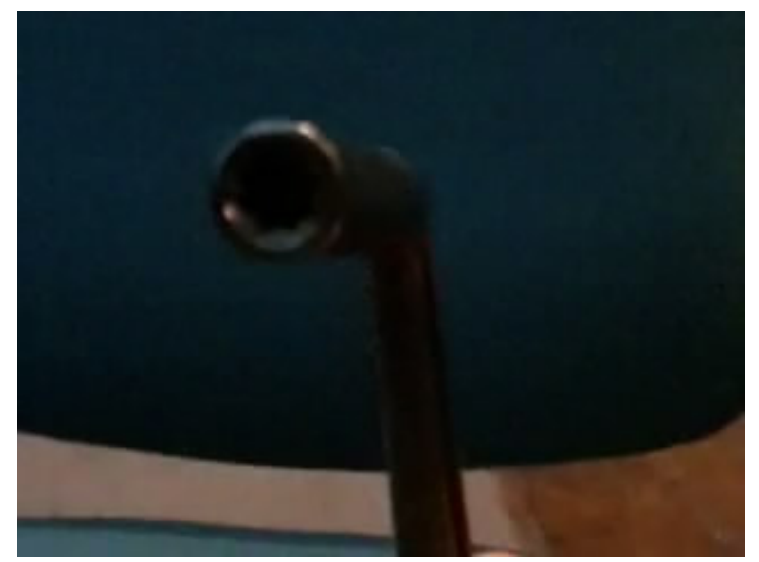

Ilustrasi 8:

Tuning Tip "Star Head" (Dokumentasi: Lutfi, 2013).

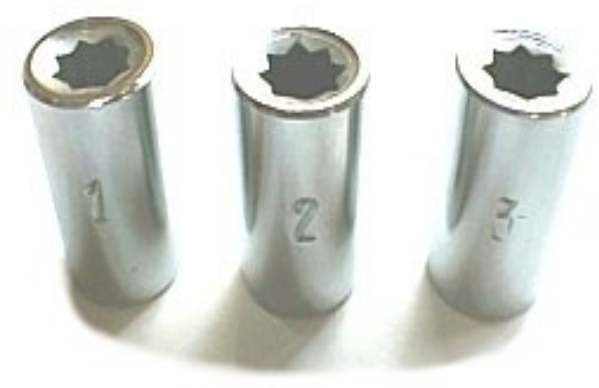

Ilustrasi 9

Tuning Tip "Star Head" (Dokumentasi: Lutfi, 2013).

Tuning tip tidak diciptakan sama, disesuaikan dengan ukuran tuning pin karena berbagai alasan termasuk tahun pembuatan piano. Bila menggunakan tuning tip dengan ukuran yang berbeda, sering akibatnya terjadi kerusakan pada tuning pin dan hammer

tuning. Hal yang sering terjadi adalah bagian atau komponen dalam piano menjadi dol (aus), sehingga tuning pin harus diganti dengan yang baru.

\section{f. Tuning Pin}

Tuning pin adalah paku pengait yang tertanam pada bilah kayu yang digunakan untuk menggulung senar. Tuning pin yang ditemukan pada hampir semua piano yang dibuat di seluruh dunia selama kurang lebih 100 tahun terakhir adalah tuning pin dengan ujung yang meruncing. Ukuran di sini mengacu pada diameter batang tertanam di Blok Pin atau Wrest Plank, bukan kepala tuning hammer. Seperti halnya ukuran tuning pin yang berbeda, tuning tip juga harus sama ukurannya agar sesuai dengan tuning pin.
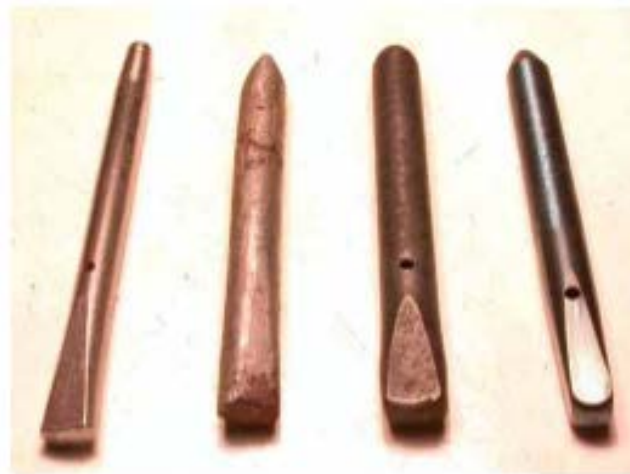

Ilustrasi 10:

Tuning Pin (Dokumentasi: Lutfi, 2013).

Tuning pin memiliki ukuran yang berbeda-beda, tergantung dari tahun pembuatan dan dari negara piano tertsebut dibuat. Ukuran tuning pin yaitu sebagai berikut:

- 1/0 - Ini adalah diameter tuning pin terkecil berukuran 0,276, tuning pin ini biasanya ditemukan di beberapa piano Eropa. Tuning pin ini baik menggunakan star head nomor \# 1 .

- $2 / 0$ - Tuning pin yang terbesar berikutnya dengan diameter berukuran 0,282 yaitu, ukuran standar pada semua piano yang dibuat di Amerika Utara dan piano yang dikirim dari Jepang atau Korea. Tuning pin dengan 
ukuran yang paling umum di sebagian piano. Tuning pin ini cocok dengan menggunakan tuning tip "star head" ukuran nomor \# 2 .

- 3/0 - Ukuran ini digunakan pada beberapa piano lama yang digantikan dengan tuning pin baru, sehingga mungkinkan memiliki tuning pin dengan diameter yang lebih besar ini, 0,286 . Biasanya ukuran ini disertai ukuran 4/0, 5/0, 6/0 atau 7/0. Ukuran tuning pin yang seperti ini hanya ditemukan di piano yang terangkai dengan tuning pin baru. Pin yang asli menjadi longgar dan digantikan dengan pin yang lebih besar. Ukuran star head yang cocok adalah \#3 atau \#4.

Dengan demikian ukuran tuning tip harus cocok dengan tuning pin.

\section{g. Petertson}

Alat ini digunakan untuk mem-bantu menala piano dengan cara yang lebih praktis. Petertson memiliki beberapa sistem yang digunakan dalam penalaan yaitu seperti: Phytagorean intonation tuning, just intonation tuning, mean-tone temperament, dan equal temperament.

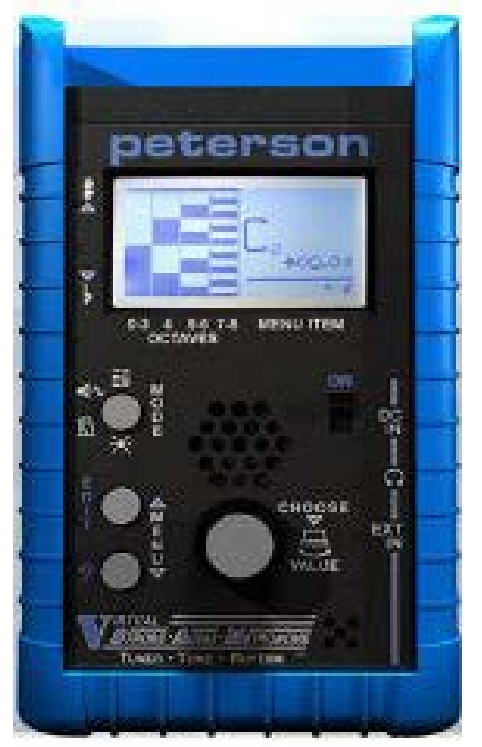

Ilustrasi 11:

Petertson (dokumentasi: Lutfi, 2013)
Petertson apabila digunakan pada nada-nada diskan maupun baskan cara kerjanya kurang akurat. Petertson memiliki standar A4 $440 \mathrm{~Hz}$. Tidak disarankan piano ditala menggunakan alat ini apabila kurang atau lebih dari standar A4 $440 \mathrm{~Hz}$. Pada senar yang sudah lama dan berkarat lebih baik menggunakan pitch kurang dari A4 $440 \mathrm{~Hz}$ karena senar akan mudah putus apabila ditala menggunakan pitch A4 $440 \mathrm{~Hz}$.

\section{Proses Penerapan Penalaan Piano oleh Musmal}

Penalaan piano di Institut Seni Indonesia Yogyakarta menggunakan sistem equal tempered. Penalaan ini dimulai dari nada A4 yang memiliki tiga senar, yang kemudian senar ditala menjadi satu pitch yang sama, dengan meredam (mute) senar yang lain dari senar ke tiga nada a dengan alat wedge mutes atau stick mutes, senar pertama disesuaikan dengan garpu tala diapason normal A4 440 Hz. Selanjutnya alat dipindahkan ke senar pertama yang diredam dan senar ke tiga ditala, kemudian setelah senar pertama dan ketiga menjadi selaras, senar kedua disamakan dengan senar pertama dan ketiga.

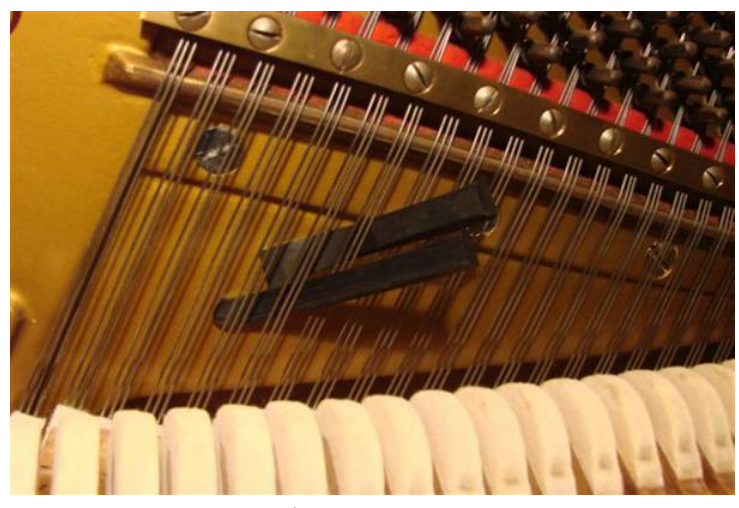

Ilustrasi 12:

Mematikan senar (Dokumentai: Lutfi, 2013)

Menala piano dengan menahan durasi nada lebih panjang, mengakibatkan beat dapat dideteksi. Beat adalah gelombang yang timbul antara dua nada yang berbeda atau tidak selaras. 
Interval unison dapat menimbulkan efek yang khas, apabila dua nada sesuai pitch. Namun bila dua nada semakin mendekati unison, kecepatan beat semakin melambat dan akhirnya menghilang, membentuk resonansi unison sempurna.

a. Tahap-tahap menyusun rangkaian equal tempered

1) Menala nada A4 dengan menggunakan garpu tala atau tuner/ penala elektrik untuk menyamakan dengan $440 \mathrm{~Hz}$.

2) Dari A4 dibandingkan dengan nada A3 interval oktaf bawah menjadi datar tanpa gelombang (flatter) atau murni (perfect).

3) Merangkai terts mayor: a) Dari nada A3 ditala terts mayor ke atas yang pertama yaitu nada Cis4; b) Dari Cis4 ditala terts mayor ke atas yang ke dua yaitu nada Eis4, vibrasi lebih cepat dua kali dari terts mayor pertama; c) Dari F4 ditala terts mayor ke atas yang ketiga yaitu nada A4, vibrasi lebih cepat dua kali dari terts mayor ke dua.

4) Dari nada A3 ditala interval kwint ke atas yaitu nada E4, lalu nada ini di kontrol (ujicoba) dengan nada A4 dalam waktu (timing) dua beat/detik.

5) Dari nada E4 dibandingkan dengan nada E3 oktaf bawah menjadi datar tanpa gelombang (flatter).

6) Dari nada E3 ditala interval kwint ke atas yaitu nada B3, lalu nada di kontrol dengan nada E4, dalam waktu dua beat/detik.

7) Dari nada B3 ditala interval kwint ke atas yaitu nada Fis4, dalam waktu dua beat/detik.
8) Dari nada Fis4 dibandingkan dengan nada Fis3 interval oktaf bawah, menjadi datar tanpa gelombang (flatter).

9) Dari nada Fis3 ditala interval kwint ke atas yaitu nada Cis4, lalu nada di kontrol dengan nada Fis4, dalam waktu dua beat/detik.

10) Dari nada Cis4 ditala interval kwint ke atas yaitu nada Gis4, dalam waktu dua beat/detik.

11) Dari nada Gis4/ As4 dibandingkan dengan nada Gis3/ As3 interval oktaf bawah menjadi datar tanpa gelombang (flatter).

12) Dari nada As3 ditala interval kwint ke atas yaitu nada Es4, lalu nada di kontrol dengan nada As4, dalam waktu dua beat/detik.

13) Dari nada Es4 ditala interval kwint ke atas yaitu nada Bes4, dalam waktu dua beat/detik.

14) Dari nada Bes4 dibandingkan dengan nada Bes3 interval oktaf bawah menjadi datar tanpa gelombang (flatter).

15) Dari nada Bes3 ditala interval kwint ke atas yaitu nada F4, lalu nada di kontrol dengan nada Bes4, dalam waktu dua beat/detik.

16) Dari nada F4 dibandingkan dengan nada F3 interval oktaf bawah menjadi datar tanpa gelombang (flatter).

17) Dari nada F3 ditala interval kwint ke atas yaitu nada C4, lalu nada di kontrol dengan nada F4, dalam waktu dua beat/detik.

18) Dari nada $C 4$ ditala interval kwint ke atas yaitu nada G4, dalam waktu dua beat/detik. 
19) Dari nada G4 dibandingkan dengan nada G3 oktaf bawah menjadi datar tanpa gelombang (flatter).

20) Dari nada G3 ditala interval kwint ke atas yaitu nada D4, lalu nada di kontrol dengan nada G4, dalam waktu dua beat/detik.

21) Dari nada D4 ditala interval kwint ke atas yaitu nada A4, lalu nada di kontrol dengan nada $\mathrm{A} 3$, dalam waktu dua beat/detik.

Peta nada-nada yang dimaksud pada tahap-tahap pebentukan rangkaian equal temperament di atas dapat ilihat pada Ilustrasi berikut ini:

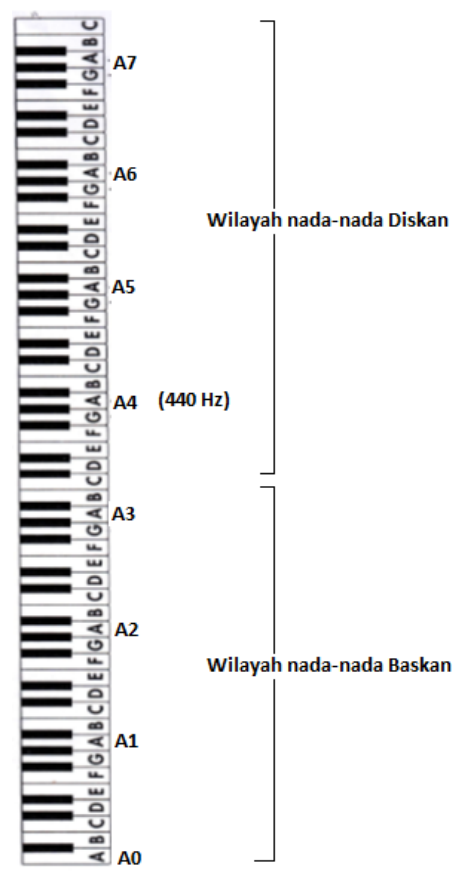

Ilustrasi 13

Posisi nada-nada pada keyboard piano

Setelah tugas merangkai (setting) equal tempered selesai seperti langkahlangkah di atas, nada-nada dapat dikontrol dengan cara mendengarkan vibrasi interval terts dari nada A3 ke Cis4, atau interval sekt dari nada E3 ke Cis4, dimainkan secara kromatis, dan dicoba untuk meng-identifikasi vibrasinya. Makin ke atas makin cepat vibrasinya, hal ini untuk menentukan jumlah beat setiap detik dalam praktik penalaan kwint secara sempurna (perfect), kemudian diturunkan nada atas sehingga menemukan dua beat/detik.

Beat yang dimaksud dalam pem-bahasan ini adalah perbedaan relatif antara frekuensi kwint atau kwart yang bisa memunculkan gelombang suara yang membentuk beat secara umum yaitu dua beat per detik. Apabila kwint dua beat/detik maka kwart harus sama. Waktu (timing) yang ideal untuk merangkai equal tempered adalah kurang lebih satu jam.

Sistematika penalaan senar-senar piano dengan menggunakan pendekatan interval ters pada jangkauan dari A3 hingga Ais4, sedangkan untuk interval sekt dilakukan pada jangkauan dari E3 hingga Eis 4.

Tabel 1

Penalaan interval terts dan sekt

\begin{tabular}{|c|c|}
\hline $\begin{array}{c}\text { Interval terts } \\
\text { Dimainkan secara } \\
\text { kromatis } \\
\end{array}$ & $\begin{array}{c}\text { Interval sekt } \\
\text { Dimainkan } \\
\text { secara kromatis }\end{array}$ \\
\hline 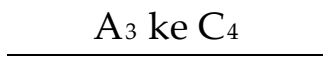 & $\mathrm{E}_{3} \mathrm{ke} \mathrm{Cis} 4$ \\
\hline Ais3 ke Cis4 & $\mathrm{F}_{3} \mathrm{ke} \mathrm{D}_{4}$ \\
\hline $\mathrm{B}_{3}$ ke Dis4 & Fis3 ke Dis4 \\
\hline $\mathrm{C}_{4} \mathrm{ke} \mathrm{E}_{4}$ & $\mathrm{G}_{3} \mathrm{ke} \mathrm{E}_{4}$ \\
\hline $\mathrm{Cis}_{4}$ ke Eis 4 & Gis3 ke Eis4 \\
\hline $\mathrm{D}_{4} \mathrm{ke} \mathrm{F}_{4}$ & $\mathrm{~A}_{3} \mathrm{ke} \mathrm{F}_{4}$ \\
\hline Dis$_{4}$ ke Fis 4 & Aiss ke Fis 4 \\
\hline $\mathrm{E}_{4} \mathrm{ke} \mathrm{G}_{4}$ & $\mathrm{~B}_{3} \mathrm{ke} \mathrm{Gis} 4_{4}$ \\
\hline $\mathrm{F}_{4} \mathrm{ke} \mathrm{A}_{4}$ & $\mathrm{C}_{4} \mathrm{ke} \mathrm{A}_{4}$ \\
\hline Fis4 ke Ais 4 & Cis 4 ke Ais 4 \\
\hline
\end{tabular}

b. Tahap-tahap menyusun rangkaian nada-nada diskan

Berpedoman pada rangkaian equal tempered yang telah selesai dirangkai, maka dalam menala nada atas (diskan) dilanjutkan dengan menyesuaikan rangkaian oktaf ke atas, semua merupakan oktaf sempurna (per- 
fect) hingga mencapai nada-nada tinggi terakhir. Adapun rangkaian penalaan nada-nada diskan adalah sebagai berikut:

1) Dari nada B4 ditala interval oktaf ke atas yaitu nada B5, dikontrol menggunakan interval kwint ke bawah yaitu dari nada B5 ke nada E5.

2) Dari nada C5 ditala interval oktaf ke atas yaitu nada C6, dikontrol menggunakan interval kwint bawah yaitu dari nada C6 ke nada F5.

3) Dari nada Cis5 ditala intervala oktaf ke atas yaitu nada Cis6, dikontrol menggunakan interval kwint ke bawah yaitu dari nada Cis6 ke nada Fis5.

4) Dari nada D5 ditala interval oktaf ke atas yaitu nada D6, dikontrol menggunakan interval kwint ke bawah yaitu nada D6 ke nada G5.

5) Dari nada Dis5 ditala interval oktaf ke atas yaitu nada Dis6, dikontrol menggunakan interval kwint bawah yaitu nada Dis6 ke nada Gis5.

6) Dari nada E5 ditala interval oktaf ke atas yaitu nada E6, dikontrol menggunakan interval kwint ke bawah yaitu dari nada E6 ke nada A5.

7) Dari nada F5 ditala interval oktaf ke atas yaitu nada F6, dikontrol menggunakan interval kwint ke bawah yaitu dari nada F6 ke nada B5.

8) Dari nada Fis5 ditala interval oktaf ke atas yaitu nada Fis6, dikontrol menggunakan interval kwint ke bawah yaitu dari nada Fis6 ke nada Bis5.

9) Dari nada G5 ditala interval oktaf ke atas yaitu nada G6, dikontrol menggunakan interval kwint ke bawah yaitu dari nada G6 ke nada C6.

10) Dari nada Gis5 ditala interval oktaf ke atas yaitu nada Gis6, dikontrol menggunakan interval kwint ke bawah yaitu dari nada Gis6 ke nada Cis6.
11) Dari nada A5 ditala interval oktaf ke atas yaitu nada A6, dikontrol menggunakan interval kwint ke bawah yaitu dari nada A6 ke nada D6.

12) Dari nada Ais5 ditala interval oktaf ke atas yaitu nada Ais6, dikontrol menggunakan interval kwint kebawah yaitu dari nada Ais6 ke nada Dis6.

13) Dari nada B5 ditala interval oktaf ke atas yaitu nada B6, dikontrol menggunakan interval kwint ke bawah yaitu dari nada B6 ke nada E6.

14) Dari nada C6 ditala interval oktaf ke atas yaitu nada C7, dikontrol menggunakan interval kwint bawah yaitu dari nada $\mathrm{C} 7$ ke nada F6.

15) Dari nada Cis6 ditala intervala oktaf ke atas yaitu nada Cis7, dikontrol menggunakan interval kwint ke bawah yaitu dari nada Cis7 ke nada Fis6.

16) Dari nada C6 ditala interval oktaf ke atas yaitu nada D7, dikontrol menggunakan interval kwint ke bawah yaitu nada D7 ke nada G6.

17) Dari nada Dis6 ditala interval oktaf ke atas yaitu nada Dis7, dikontrol menggunakan interval kwint bawah yaitu nada Dis7 ke nada Gis6.

18) Dari nada E6 ditala interval oktaf ke atas yaitu nada E7, dikontrol menggunakan interval kwint ke bawah yaitu dari nada E7 ke nada A6.

19) Dari nada F6 ditala interval oktaf ke atas yaitu nada F7, dikontrol menggunakan interval kwint ke bawah yaitu dari nada F7 ke nada B6.

20) Dari nada Fis6 ditala interval oktaf ke atas yaitu nada Fis7, dikontrol menggunakan interval kwint ke bawah yaitu dari nada Fis7 ke nada Bis6.

21) Dari nada G6 ditala interval oktaf ke atas yaitu nada G7, dikontrol menggunakan interval kwint ke bawah yaitu dari nada G7 ke nada C7. 
22) Dari nada Gis6 ditala interval oktaf ke atas yaitu nada Gis7, dikontrol menggunakan interval kwint ke bawah yaitu dari nada Gis7 ke nada Gis7.

23) Dari nada A6 ditala interval oktaf ke atas yaitu nada A7, dikontrol menggunakan interval kwint ke bawah yaitu dari nada A7 ke nada D7.

24) Dari nada Ais6 ditala interval oktaf ke atas yaitu nada Ais7, dikontrol menggunakan interval kwint ke bawah yaitu dari nada Ais7 ke nada Dis7.

25) Dari nada B6 ditala interval oktaf ke atas yaitu nada B7, dikontrol menggunakan interval kwint ke bawah yaitu dari nada B7 ke nada E7.

26) Dari nada $C 7$ ditala interval oktaf ke atas yaitu nada C8, dikontrol menggunakan interval kwint ke bawah yaitu dari nada C7 ke nada F7. Rangkaian nada diskan di atas diselesaikan dalam waktu satu jam, selanjutnya merangkai nada baskan dari nada E3 hingga Bes4.

c. Langkah-langkah merangkai Baskan Rangkaian nada-nada baskan disusun melalui tahap-tahap sebagai berikut:

1) Dari nada Es3 ditala interval oktaf ke bawah yaitu nada Es2, dikontrol menggunakan interval kwint ke atas yaitu dari nada Es2 ke nada Bes2.

2) Dari nada D3 ditala interval oktaf ke bawah yaitu nada D2, dikontrol menggunakan interval kwint ke atas yaitu dari nada D2 ke nada A2.

3) Dari nada Des3 ditala interval oktaf ke bawah yaitu nada Des2, dikontrol menggunakan interval kwint ke atas yaitu dari nada Des2 ke nada As2.

4) Dari nada C3 ditala interval oktaf ke bawah yaitu nada C2, dikontrol menggunakan interval kwint ke atas yaitu dari nada C2 ke nada G2.
5) Dari nada B2 ditala interval oktaf ke bawah yaitu nada B1, dikontrol menggunakan interval kwint ke atas yaitu dari nada B1 ke nada Ges2.

6) Dari nada Bes2 ditala interval oktaf ke bawah yaitu nada Bes1, dikontrol menggunakan interval kwint ke atas yaitu dari nada Bes1 ke nada F2.

7) Dari nada A2 ditala interval oktaf ke bawah yaitu nada A1, dikontrol menggunakan interval kwint ke atas yaitu dari nada A1 ke nada E2.

8) Dari nada As2 ditala interval oktaf ke bawah yaitu nada As1, dikontrol menggunakan interval kwint ke atas yaitu dari nada As1 ke nada Es2.

9) Dari nada G2 ditala interval oktaf ke bawah yaitu nada G1, dikontrol menggunakan interval kwint ke atas yaitu dari nada G1 ke nada D2.

10) Dari nada Ges2 ditala interval oktaf ke bawah yaitu nada Ges1, dikontrol menggunakan interval kwint ke atas yaitu dari nada Ges1 ke nada Des2.

11) Dari nada F2 ditala interval oktaf ke bawah yaitu nada F1, dikontrol menggunakan interval kwint ke atas yaitu dari nada F1 ke nada C2.

12) Dari nada E2 ditala interval oktaf ke bawah yaitu nada E1, dikontrol menggunakan interval kwint ke atas yaitu dari nada E1 ke nada B1.

13) Dari nada Es2 ditala interval oktaf ke bawah yaitu nada Es1, dikontrol menggunakan interval kwint ke atas yaitu dari nada Es1 ke nada Bes1.

14) Dari nada D2 ditala interval oktaf ke bawah yaitu nada D1, dikontrol menggunakan interval kwint ke atas yaitu dari nada D1 ke nada A1.

15) Dari nada Des2 ditala interval oktaf ke bawah yaitu nada Des1, dikontrol menggunakan interval kwint ke atas yaitu dari nada Des1 ke nada As1.

16) Dari nada $C 2$ ditala interval oktaf ke bawah yaitu nada C1, dikontrol 
menggunakan interval kwint ke atas yaitu dari nada $\mathrm{C} 1$ ke nada G1.

17) Dari nada B1 ditala interval oktaf ke bawah yaitu nada B0, dikontrol menggunakan interval kwint ke atas yaitu dari nada B0 ke nada Ges1.

18) Dari nada Bes1 ditala interval oktaf ke bawah yaitu nada Bes0, dikontrol menggunakan interval kwint ke atas yaitu dari nada Bes0 ke nada F1.

19) Dari nada A1 ditala interval oktaf ke bawah yaitu nada A0, dikontrol menggunakan interval kwint ke atas yaitu dari nada A0 ke nada E1.

Setelah menyelesaikan tiga rangkaian dalam menala equal tempered seperti di atas dapat dikontrol dengan memainkan trinada minor dari C4 (midle C) ke atas dan memainkan trinada mayor dari $\mathrm{C} 4$ ke bawah.

d. Proses memutar tuning hammer dan meredam senar dengan mutes

Memutar dengan menggunakan tuning hammer bertujuan agar senar memiliki ketegangan yang merata di seluruh panjang senar yang berarti ketegangan harus sama dimiliki tiga senar yang berbeda. Hal ini sangat penting dilakukan apabila hal ini tidak diperoleh maka senar tidak berbunyi selaras. Pengaturan memutar pin tuning agar seimbang berkenaan dengan menarik senar dengan ketat.

Ketika tuning hammer diletakkan lurus di atas tuning pin, tuning hammer ditarik sedikit ke belakang dari penala, di sini tuning hammer belum diputar ke arah kanan. Ketegangan senar menjadi ketat, bahkan sebelum tuning hammer diputar. Gerakan menarik tuning hammer ke belakang sangat berpengaruh walaupun gerakan kecil, karena hal ini sudah dapat merubah tingkat ketegangan senar (pitch).

Perubahan ketegangan senar ini walaupun kecil, sudah bisa ditangkap oleh telinga. Pada saat memutar tuning hammer dianjurkan agar memakai tangan kanan dengan alasan posisi di instrumen yang nyaman bagi penala, tangan kanan lebih kuat karena sering digunakan sehari-hari dan lebih terlatih dalam menentukan kekuatan yang dibutuhkan. Di bawah ini adalah Ilustrasi posisi tuning pin pada piano.

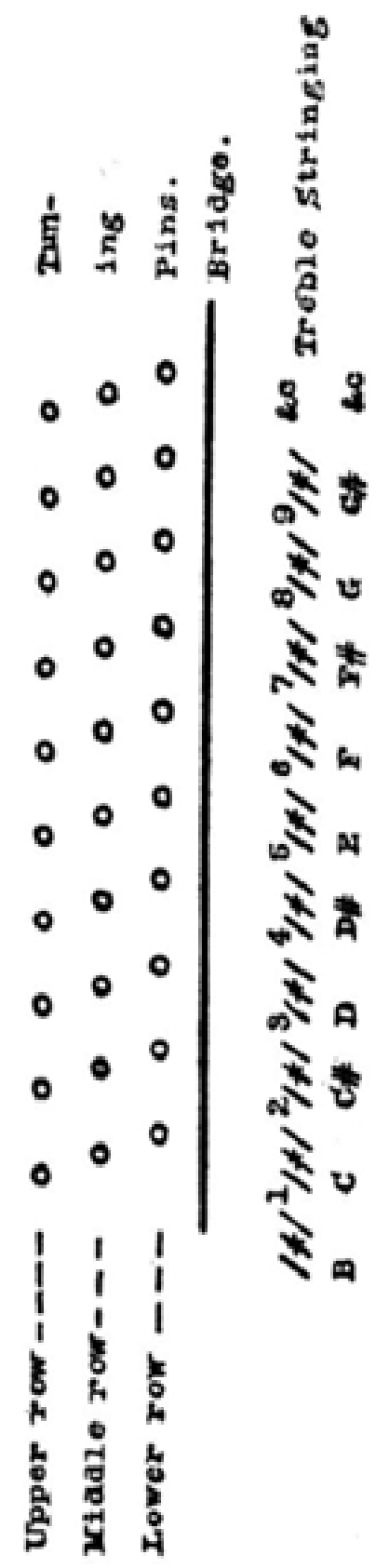

Ilustrasi 14:

Posisi tuning pin pada piano

Upper row digunakan untuk snar pertama. Middle row untuk snar ke dua, dan lower row digunakan untuk snar ke tiga. Satu 
mutes digunakan menala nada unison. Ketika mute diletakkan di snar nomor satu di antara nada unison $\mathrm{B}$ dan $\mathrm{C}$, mute akan meredam snar pertama pada snar $C$ dan snar ke tiga nada $B$, sehingga snar $C$ yang pertama kali dapat ditala adalah snar ke tiga. Selanjutnya mutes diletakkan pada nomor dua antara nada C dan Cis. Mutes akan meredam snar ke tiga dari nada $C$ dan snar pertama dari nada Cis, sehingga dapat ditala snar pertama dari nada C. Snar ke dua dari nada C dapat ditala dengan menyamakan snar pertama dan ke tiga yang telah selesai ditala sebelumnya. Hal ini dilakukan ketika menala nada yang mempunyai tiga snar. Apabila pada dua snar hanya menggunakan satu mutes untuk meredam snar, sehingga snar yang satu dapat ditala. Pada satu snar bass bawah, mutes tidak digunakan untuk meredam snar. Penalaan pada nada bass, disamakan dengan nada-nada oktaf atas.

\section{Pengalaman sebagai PianoTuner}

Selama 24 tahun Musmal menjadi penala (tukang stem) di berbagai tempat di Jawa Tengah dan Jakarta, banyak pemilik piano belum memahami masalah-masalah seperti seberapa pentingkah harus menala piano, dan apakah piano akan rusak apabila tidak ditala. Ia berpendapat bahwa piano yang tidak ditala bertahun-tahunpun tidak akan rusak, tetapi konsekuensinya adalah nada yang terdengar sumbang. Hal ini tergantung pada kemampuan pendengar pemilik atau pemain piano untuk mendeteksi suara piano yang benar dan tidak sumbang.

Menurut Musmal piano sebaiknya ditala dua kali dalam satu tahun sesuai dengan perubahan iklim di Indonesia yang pada umumnya terdapat dua musim, yaitu musim penghujan dan musim panas atau kemarau. Perubahan kelembaban udara terjadi dari musim kemarau ke musim hujan, dan juga dari musim hujan ke musim kemarau (masa pancaroba). Musim hujan terjadi pada bulan September hingga bulan Februari, sedangkan musim panas atau kemarau terjadi pada bulan Maret hingga bulan Agustus.

Enam bulan selama musim hujan merupakan waktu yang panjang, kelembaban udara demikian tinggi, sehingga dalam kondisi demikian papan soundboard akan dapat lebih stabil dengan memasang pemanas (heater). Demikian juga sebaliknya selama musim panas (kemarau) meskipun kelembaban udara demikian rendah, papan soundboard dapat bertahan stabil dengan heater. Maka dari uraian di atas, ia menyarankan sebaiknya menala piano dua kali setahun, pertama pada awal musim hujan kira-kira bulan September, dan pada awal musim panas atau kemarau kira-kira pada bulan Maret.

Walaupun demikian, seringkali beberapa orang dalam melakukan penalaan piano tidak hanya tergantung pada kualitas piano atau perubahan kelembaban udara di dalam ruangan di mana piano ditempatkan, tetapi juga tergantung oleh kemampuan pendengaran pemilik atau pemain piano yang mendeteksi tingkat kesumbangan apabila piano tidak tala. Dua kali setahun menala piano merupakan keputusan yang ideal, namun bila piano jarang dimainkan, satu kali setahun sudah cukup, walau itu tidak disarankan. Menala piano yang dilakukan oleh Musmal menurutnya me-rupakan keterampilan yang dapat dikuasai dan dipelajari, dan tentu saja dengan ketekunan dan kesabaran serta ketelitian mengidentifikasi pitch dan beat.

\section{Cara Perawatan Piano}

Piano merupakan alat musik yang menunjang dalam menyampaikan perasaan seni, maka dari itu piano perlu dirawat secara berkala. Selain ditala oleh seorang yang ahli penala piano, pemilik piano juga harus bisa merawat pianonya sendiri. Beberapa contoh untuk perawatan piano yang di karenakan kelembaban udara dan gangguan lainnya adalah sebagai berikut. 
Pertama, pencegahan terhadap gangguan dari kelembaban yaitu, pada waktu hujan tutuplah jendela. Piano jangan ada yang terbuka karena berakibat menghambat gerakan kerja mekanik piano. Pada saat panas bukalah jendela supaya ada sirkulasi udara masuk. Kain penutup piano agar sering dijemur agar piano tidak lembab. Tempatkan piano jangan didekat jendela, apabila harus diletakkan didekat jendela, pasanglah tirai yang tebal. Jangan menempatkan piano didekat tempat yang lembab dan terkena sinar matahari langsung.

Kedua, pencegahan terhadap gangguan yang dikarenakan kekeringan udara. Kekeringan udara menyebabkan keluar suara janggal atau suara getaran (resonansi), yang dikarenakan bagian kayu misalnya soundboard atau bagian exterior terdapat keretakan. Tuning pin juga akan kendur akibat kayu menciut, apabila tidak stabil maka harus diganti tuning pin baru. Suara getaran yang tidak berhenti tersebut mengakibatkan gerakan damper wire tidak lancar.

Ketiga, gangguan yang di karenakan perubahan temperatur yang drastis, mengakibatkan tuning menjadi kacau. Ruangan dingin yang tiba-tiba dipanaskan dengan heater secara men-dadak mengakibatkan soundboard men-dapat pengaruh sehingga tekanan snar dapat berubah. Perubahan temperatur yang mendadak juga mengakibatkan kondensasi air di udara, sehingga snar dan tuning pin akan terpengaruh oleh air dan akibatnya mudah berkarat. Udara panas dari heater atau udara ringan dari AC yang terkena piano dalam waktu yang lama mengakibatkan kabinet atau bagian lain dari kayu akan bengkak atau pecah, sehingga intonasi akan berubah. Jangan letakkan piano dibawah AC supaya tidak terkena tetesan air.

Keempat, bulu kempa yang dimakan rayap, bagian dari kulit atau kabinet berubah, dan gangguan oleh tikus umum terjadi pada upright piano. Tikus masuk kedalam pi- ano dari lubang pedal mengakibatkan kerusakan yang besar. Tikus yang bersarang di dalam piano dapat mengakibatkan mekanik piano rusak, untuk itu piano harus sering dimainkan.

Kelima, perawatan piano bagian exterior (luar) supaya mengkilap tidak lekas pudar, yaitu apabila ada debu di atas permukaan piano dapat dibersihkan dengan kain kasa atau kain lain yang lembut seperti kain planel. Jangan digosok keras-keras karena pasir dan debu akan mengakibatkan goresan di permukaan. Bersihkan dengan lap kering, sebaiknya lap diganti sesudah dipakai untuk bagian luar. Apabila banyak kotoran yang menempel, pakailah kain yang dibasahi air dan diperas dengan keras. Alat dan bahan pembersih yang dijual di tokotoko yang mengandung alkohol akan mengakibatkan tuts pecah. Maka dari itu perlu ditanamkan disiplin bahwa sebelum bermain piano tangan harus dicuci dulu.

Hal-hal lain yang perlu diperhatikan adalah jangan meletakkan barang di atas piano, terutama barang-barang dari kaca karena akan mengakibatkan suara menjadi bergema. Hindari agar piano tidak kena air, jika harus mengepel lantai di sekitar piano, jangan tumpahkan air atau mengepel dengan kain pel yang basah. Peraslah kain pel itu terlebih dahulu khusus untuk lantai di sekitar piano agar air tersebut tidak menguap masuk ke dalam piano.

Hal yang paling baik adalah, letakkanlah piano di atas karpet sehingga tidak perlu dipel dengan air tetapi dibersihkan dengan vacum cleaner. Perhatikanlah letak atau posisi piano, jangan sampai berada di bawah atap yang bocor. Belilah tutup piano untuk menutupi piano dari debu dan benda asing. Tutup piano akan mengurangi terjadinya goresan pada piano.

\section{Penutup}

Piano adalah sebuah instrumen chordophone terdiri dari 200 snar yang ketegangan snarnya sangat tergantung dari 
kelembaban udara. Indonesia yang sangat lembab mengakibatkan ketegangan snar berubah. Pada musim hujan ketegangan snar menjadi turun dan pada musim kemarau ketegangan snar menjadi meningkat sehingga pitch berubah tinggi. Hal ini mengakibatkan penalaan harus dilakukan secara teratur.

Proses penalaan piano menggunakan sistem equal tempered yaitu sistem sistem yang umum digunakan untuk menala piano pada saat ini, menggunakan sistem equal tempered dikarenakan dapat membagi oktaf menjadi 12 nada yang sama. Sebelumnya ada beberapa sistem, tetapi apabila memakai sistem penalaan yang lain maka akan mengakibatkan dalam satu oktaf terdapat lebih dari 12 nada semitone. Di dalam sistem equal tempered, yang terpenting adalah merangkai (setting) bagian tempered dari nada E3 sampai dengan Bes4, di mana bagian ini digunakan sebagai acuan dalam menala nada-nada diskan dan baskan. Proses penalaan oleh Musmal secara keseluruhan tidak banyak menggunakan alat elektronik di karenakan alat tersebut diyakini kurang akurat apabila diterapkan pada peenalaan nadanada diskan dan baskan.

Alat elektronik tidak bisa menangkap pitch dengan tepat pada bagian nada paling rendah dan paling tinggi. Penala hanya menggunakan alat elektronik ketika menala pada A4 $440 \mathrm{~Hz}$. Setelah proses penalaan piano dilakukan, diperlukan pemahaman agar semua yang memainkan alat musik piano bisa menjaga dan merawat pianonya dengan baik. Adapun perawatan dan pemeliharaan piano yang harus diperhatikan adalah: menutup piano dan memasang kain penutup di atas tuts piano sehabis dimainkan, menjaga kebersihan, jangan meletakkan barang berat di atas piano, selalu menjaga suhu udara, jangan lupa agar piano ditala.

\section{Catatan:}

Penelitian ini dilakukan dalam rangka penulisan Skripsi S1 Seni Musik di Jurusan Musik,
Fakultas Seni Pertunjukan, Institut Seni Indonesia Yogyakarta, diujikan tahun 2014.

\section{Referensi}

Barbour, Murray J. 1951. Tuning and Temperament: A Historical Survey. USA: Michigan State Collage Press,

Brinsmead, Edgar. 1879. The History of the Piano Forte: Theory of Sound $\mathcal{E}$ Also of the Music and Musical Instrumen of the Ancients. London: Novello, Ewer \& CO.

Culver, Charles A. 1956. Musical Acoustic. New York: Mc Graw Hill Book Company.

Fine, Larry. 1950. The Piano Book: A Guide to Buying a New or Used Piano. Massachusetts: Brookside Press-Boston.

Flischer, J. Cree. 1975. Piano Tuning: A Simple and Accurate Method for Amateurs. New York: Dover Publications Inc.

Holland, Frank W. 1980. "Piano Forte" dalam Stanly Sadie (ed.), The New Grove Dictionary of Music and Musician, Volume 19. London: Macmillan Publisher Limited.

Lindley, Mark. 1980. "Just intonation", dalam Stanley Sadie (ed.), The New Grove Dictionary of Music and Musician, Volume 18. London: Macmillan Publisher Limited.

Lindley, Mark. 1980. “Temperamen”, dalam Stanley Sadie (ed.), The New Grove of Dictionary Music and Musician, Volume 25. London: Macmillan Publisher Limited.

Lindley, Mark. 1980. "Tuning", dalam Stanley Sadie (ed.), The New Grove Dictionary of Music and Musician, Volume 25. London: Macmillan Publisher Limited.

Musmal. 2013. “Melaras Piano Dengan Sistem Equal Tempered", dalam Promusika, Jurnal Pengkajian, Penyajian, dan Penciptaan Musik, Vol. 1, No. 1, 
April 2013. Yogyakarta: Jurusan Musik FSP ISI Yogyakarta.

Rastall, Richard. 1980. "Pitch", dalam Stanley Sadie (ed.), The New Grove Dictionary of Music and Musician, Volume 19. London: Macmillan Publisher Limited.
Sitorus, Eritha R. 1988. “Penalaan Nada Pada Alat-alat Musik yang Memakai Klafikatur", Skripsi S-1 Seni Musik, Yogyakarta: Jurusan Musik FSP Institut Seni Indonesia Yogyakarta 